\title{
Rectal biopsy in the investigation of constipation
}

\author{
A Ghosh, D M Griffiths
}

\begin{abstract}
Aims-To develop criteria to prevent unnecessary rectal biopsies in constipated children.

Methods-A retrospective review of 186 rectal biopsies from 141 children, comparing the age at onset of symptoms with the diagnosis of Hirschsprung's disease.

Results-All of the 17 children with Hirschsprung's disease had the onset of symptoms before the age of 4 weeks. Twenty seven children had delayed passage of meconium (more than 48 hours) of whom 10 had Hirschsprung's disease. Three children with Hirschsprung's disease were referred after the neonatal period (2 months, 11 months, and 3 years) but all had the onset of symptoms before 4 weeks of age.

Conclusion-If the age at onset of constipation is after the neonatal period, a rectal biopsy is unnecessary.

(Arch Dis Child 1998;79:266-268)
\end{abstract}

Keywords: Hirschsprung's disease; constipation; rectal biopsy

Constipation is a very common problem among children. Most cases do not have an underlying disease requiring surgery and are successfully managed by general practitioners and paediatricians. However, a number of these children are referred for rectal biopsy to exclude a possible diagnosis of Hirschsprung's disease.

Hirschsprung's disease is an abnormality of the enteric nervous system. It can be fatal and so requires early diagnosis and treatment. The definitive diagnosis of this condition is based on the histological appearance of the rectal biopsy characterised by the absence of para-

Accepted 9 March 1998

Table 1 Age at presentation and clinical features of children with Hirschsprung's disease

\begin{tabular}{|c|c|c|}
\hline Patient/Sex & Age & Clinical features \\
\hline $1 / \mathrm{M}$ & 2 days & \multirow{11}{*}{$\begin{array}{l}\text { Failure to pass meconium, abdominal distension, bilious } \\
\text { vomiting }\end{array}$} \\
\hline $2 / \mathrm{M}$ & 3 days & \\
\hline $3 / \mathrm{M}$ & 2 days & \\
\hline $4 / \mathrm{F}$ & 1 day & \\
\hline $5 / \mathrm{F}$ & 3 days & \\
\hline $6 / M$ & 3 days & \\
\hline $7 / \mathrm{M}$ & 3 days & \\
\hline $8 / \mathrm{F}$ & 3 days & \\
\hline $9 / M$ & 1 day & \\
\hline $10 / \mathrm{F}$ & 3 days & \\
\hline $11 / \mathrm{F}$ & 2 day & \\
\hline $12 / \mathrm{M}$ & 12 days & Bilious vomiting, abdominal distension \\
\hline $13 / \mathrm{M}$ & 2 days & \\
\hline $14 / \mathrm{F}$ & 3 weeks & Enterocolitis, constipation from birth \\
\hline $15 / F$ & 2 months & $\begin{array}{l}\text { Severe constipation from birth, father has Hirschsprung's } \\
\text { disease }\end{array}$ \\
\hline $16 / \mathrm{M}$ & 11 months & $\begin{array}{l}\text { Severe constipation from birth, recurrent abdominal } \\
\text { distension }\end{array}$ \\
\hline $17 / \mathrm{M}$ & 3 years & $\begin{array}{l}\text { Severe constipation from birth, father and older brother with } \\
\text { Hirschsprung's disease }\end{array}$ \\
\hline
\end{tabular}

sympathetic ganglia and the presence of hypertrophied nerve trunks in the bowel wall.

A large number of children with chronic constipation were referred to our centre for rectal biopsy. In most cases the clinical picture was not suggestive of any underlying disease and the incidence of Hirschsprung's disease in this group of children was very low. However, we could not refuse the referring doctor's request for biopsy as we had no objective data to support our opinion. We therefore decided to perform this retrospective study to see whether our general impression was true, and to see if we could establish criteria that would reliably and consistently identify children with Hirschsprung's disease and thereby avoid the trauma and expense of unnecessary biopsies in the others.

\section{Materials and methods}

The names and record numbers of all children who had rectal biopsies to exclude Hirschsprung's disease between 1 January 1993 and 31 December 1995 were obtained from the histopathology department. A total of 142 children had had biopsies, the case notes of 141 of these could be recovered (biopsy number 142 was not from a child with Hirschsprung's disease). A detailed retrospective review was made of all 141 case notes.

The histological diagnosis was usually made on haematoxylin and eosin staining of the biopsy specimen with at least 100 serial sections looked at in detail. Acetylcholinesterase was used occasionally, but not as the primary method of diagnosis.

For children younger than 1 year, a Noblett suction rectal biopsy was usually performed. In older children, or following repeated failure of the Noblett biopsy, an open, transanal rectal biopsy under general anaesthesia was performed at least $1 \mathrm{~cm}$ above the pectinate line.

\section{Results}

Of the 141 children having biopsies in this three year period, 17 (12\%) had Hirschsprung's disease. Age at diagnosis ranged from 1 day to 3 years. The other 124 children did not have Hirschsprung's disease and their ages at biopsy ranged from 1 day to 13 years.

Table 1 outlines the mode of presentation of the 17 children with Hirschsprung's disease. Fourteen presented to us in the neonatal period, 13 with intestinal obstruction and one with enterocolitis. The remaining three children presented after the neonatal period despite having had severe symptoms from birth.

Of the 141 children, 27 had a history of delayed passage of meconium (more than 48 hours after birth); 10 of these were children with Hirschsprung's disease. 


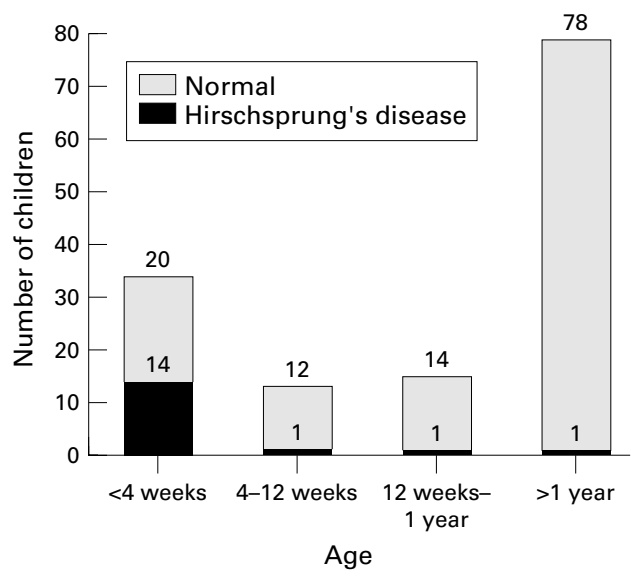

Figure 1 Age at which rectal biopsies were performed.

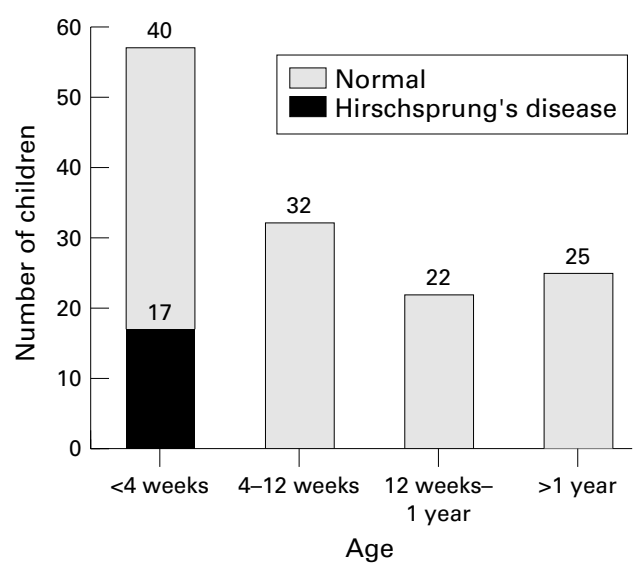

Figure 2 Age at onset of constipation.

Figure 1 shows the age at which the rectal biopsies were performed (which correlates well with the age of presentation to our surgical unit). Most children were over 1 year old when they had biopsies. Of the 34 children having biopsies within the neonatal period, 14 had Hirschsprung's disease. Hirschsprung's disease was diagnosed in a further three children presenting after the neonatal period.

Figure 2 shows the age of onset of constipation (which is different from the age of presentation to our unit). By "constipation" we refer to decreased frequency of bowel movements (fewer than three each week), or a difficulty in defecation, which is perceived by the parents as a problem, requiring medication (oral or rectal) or manual intervention by the parents. This included anal stimulation with a cotton bud, holding the buttocks apart, and manual evacuation.

Fifty seven children had symptoms starting in the first four weeks of life including all 17 with Hirschsprung's disease. The remaining 84 children did not have symptoms in the neonatal period and none of them had Hirschsprung's disease. The history of age of onset of symptoms was available in 136 of the 141 children $(96 \%)$. This crucial history was available in $100 \%$ of the children who had constipation beginning in the neonatal period including all children with Hirschsprung's disease. The five children in whom this history could not be
Table 2 Additional features in history and examination

\begin{tabular}{lll}
\hline Symptom & $\begin{array}{l}\text { Hirschsprung }+v e \\
(n=17)\end{array}$ & $\begin{array}{l}\text { Hirschsprung -ve } \\
(n=124)\end{array}$ \\
\hline $\begin{array}{l}\text { Bleeding per rectum } \\
\text { Anal fissures }\end{array}$ & 0 & $37(30 \%)$ \\
$\begin{array}{l}\text { Severe behavioural/ } \\
\text { emotional problems }\end{array}$ & 0 & $14(11 \%)$ \\
$\begin{array}{l}\text { Soiling } \\
\text { Enterocolitis }\end{array}$ & 0 & $10(8 \%)$ \\
\hline
\end{tabular}

Table 3 Rectal biopsies: failures

\begin{tabular}{lcc}
\hline Type & Total performed & Failures \\
\hline Suction & 74 & $26(35 \%)$ \\
Open & 100 & $14(14 \%)$ \\
Operative & 12 & 0 \\
Total & 186 & $40(22 \%)$ \\
\hline
\end{tabular}

obtained from the notes were all older than 1 year (three were teenagers) and none had Hirschsprung's disease.

Table 2 outlines the presence of some additional features in the history and examination of these children.

A total of 186 biopsies were performed in the 141 children. Table 3 outlines the number of biopsies that had to be repeated because of technical failure (biopsy too small, too close to the pectinate line, or too superficial, or because of misinterpretation of the slide). We had an overall failure rate of $22 \%$.

\section{Discussion}

All 17 children with Hirschsprung's disease had the onset of constipation within the neonatal period; a history of the age of onset of constipation was available in all these children. Conversely, none of the children whose problem started after the neonatal period had Hirschsprung's disease.

Most textbook descriptions of Hirschsprung's disease suggest that symptoms should appear early in the neonatal period. However, the diagnosis continues to be entertained in older children presenting much later. Several studies have shown a low detection rate of Hirschsprung's disease in large numbers of children having biopsies for constipation, ${ }^{12}$ but have not suggested any criteria for deciding which children do not need a biopsy. The single previous study that addressed this issue also showed that the age of onset of constipation correlated with a positive diagnosis. ${ }^{3}$ Studies looking at large series of children with Hirschsprung's disease ${ }^{4}$ as well as adult patients have reported onset of symptoms from birth even in late diagnosed cases. ${ }^{56}$

Although one might think that parents would be unable to go back in time and recall the bowel pattern of their child as a baby, they were always able to remember any problems occurring in the neonatal period. Although parents might not be able to answer the question "when did the constipation first begin?" when put in that direct fashion, they were always able to correlate onset of symptoms with normal developmental events such as a change in feeding from the breast to bottle, onset of weaning, and toilet training. This 
crucial history - the age at which the symptoms started-is therefore available, but it needs to be carefully sought, and a detailed neonatal history taken by the doctor.

A rectal biopsy is normally a straightforward procedure, however, there can be several difficulties associated with it. In our study, open rectal biopsies were more successful than suction rectal biopsies. The biopsy may be taken too close to the pectinate line (this is an error in technique) making it difficult to differentiate from physiological aganglionosis. It can be too superficial, resulting from a combination of technical error and mucosal oedema caused by rectal washouts. These problems are more common with suction biopsies but an open rectal biopsy is a formal surgical procedure requiring general anaesthesia and therefore not ideal for a neonate.

Six of the 40 failed biopsies (three open and three suction rectal biopsies) were not repeated as the children were doing well on follow up. There was no morbidity or mortality associated with the biopsies.

Children with Hirschsprung's disease do not commonly have problems with bleeding per rectum or anal fissures (as opposed to children with functional constipation). Conversely, children who do not have Hirschsprung's disease are not at risk of developing enterocolitis (table 2).

\section{Conclusion}

In a child with constipation, it is critical to ascertain when the problem began. If the onset is within the neonatal period, two rectal suction biopsies taken at least $1.5 \mathrm{~cm}$ above pectinate line and deep enough to include the submucosal myenteric plexus should be taken (one fresh and one in formalin). These should be sent immediately to an experienced paediatric pathologist who has the facilities for both routine stains and acetylcholinesterase histochemistry.

If the onset of constipation is after the neonatal period, the child is unlikely to have Hirschsprung's disease and therefore a rectal biopsy is unnecessary.

Had these criteria been followed, all 17 cases of Hirschsprung's disease in our study would have been diagnosed and we would have avoided $60 \%$ of the rectal biopsies.

1 Mishalany $\mathrm{H}$. Seven years' experience with idiopathic unremitting chronic constipation. F Pediatr Surg 1989;24:360-2.

2 Schofield DE, Devine W, Yunis EJ. Acetylcholinestrasestained suction rectal biopsies in the diagnosis of Hirschsprung's disease. ₹ Pediatr Gastroenterol Nutr 1990;11:221-8.

3 Landman GB. A five year chart review of children biopsied to rule out Hirschsprung's disease. Clin Pediatr 1987;26: 288-91.

4 Kosloske AM, Goldthorn JF. Early diagnosis and treatment of Hirschsprung's disease in New Mexico. Surg Gyne Obstet 1984;158:233-7.

5 Hung WT, Chiang TP, Tsai YW, et al. Adult Hirschsprung's disease. F Pediatr Surg 1989;24:363-6.

6 Fairgrieve J. Hirschsprung's disease in the adult. $B r f$ Surg 1962;50:506-14. 